not be justified in doing the operation, just as no Catholic physician or surgeon is justified in conniving at the practice of race-suicide by telling a patient, who may consult him on the subject, how the thing is done.

From the point of view of a sociolcgist it seems to me that the crux of the question raised lies in the pertinent query of Dr. Robert Jones: What is to be the limit of sterilisation to prevent the reproduction of the unfit? If we sterilise to prevent the propagation of epilepsy and thus improve the race, why not sterilise to prevent the reproduction of the mentally degenerate and the physically defective, the child with inborn tendencies to all forms of wickedness and criminality, and the child with inherited weakness whether of disease or of constitution? I am afraid that if this were done we would have to sterilise the major part of the human race. Then who would be the final arbiter in sterilisation, and would the father, when it was found that one child was unfit, submit himself to be sterilised to prevent more unfits? It is to be noted that Dr. Ewart, either unwittingly or wittingly, did not allude to this vital point of the limitation of sterilisation.

There is just one other point I would wish to place before your readers, and it was no doubt in the mind of Dr. Robert Jones when he wrote that sterilisation would not possibly improve the moral and mental qualities of the race, for the presence of human weakness was a moral appeal to the strong and served a useful purpose in the moral development of any people. While I am aware of the difference between the prevention by physical means of the birth of the unfit for the good of the race and the destruction of the unfit by the same means and for the same object, there is a dangerously narrow border-line between the two, and transition from the one act to the other would be easy. The arguments that could be urged for the one act could be urged with equal logic and force for the other. To destroy the unfit for the physical good of the race would be a complete reversal of the hands of the clock of civilisation, for it would reduce man to the ethical level of the brute. In my opinion, the lion or the tiger, which seems to have no control over its vicious impulses and devours weaker animals for its own preservation and for the joys and pleasures of its life, would have as high an ethical standard as that of the man who would destroy the unfit for what would be practically his own ease and comfort, and to avoid the practice of self-denial and the control of his inherent selfish and lustful desires for the satiations of a luxurious life. As a matter of fact, the ethics of the brute would be higher than those of man, for in its case the question of self-preservation is involved in its destruction of weaker animals, and the brute does not kill or even acquiesce in the destruction of its own unfit, but, on the contrary, it will guard and protect its young, whether fit or unfit, even to the point of sacrificing its own life.

I cannot conclude without thanking Dr. Robert Jones for bis luminous and closely reasoned letter. The value of his opinion lies in the fact that it is the opinion of a distinguished alienist whose sound judgment is based on mature experience in the observation and treatment of mental disease. His opinion on this question is, I am quite sure, the opinion of every Christian father and every Christian p'ysician and surgeon in the civilised world.

I am, Sir, yours faithfully,

Thomas Colvin, M.D., M.S. Glasg., J.P.

Glasgow, August 25th, 1911.

\section{THE CURIOUS HISTORY OF A SWALLOWED PIN.}

To the Editor of THE LANCET.

SrR,-I was much interested in reading the case related by Dr. Wilfred Balgarnie in THE LANCET of August 19th, p. 500, nnder the above title. It reminded me of a somewhat similar circumstance which occurred during $m y$ practice in Paris towards 1862 or 1863, and I fancy that, being at that time your " own correspondent," I may have referred to it in one of my weekly letters.

In the Rue de Matignon, Faubourg St. Honoré, where I lived, I had a neighbour, a Hungarian, who was a working glover. One morning the glover's wife brought into my consulting-room a screaming baby boy of the crawling age-i.e., 18 months old.
The mother, evidently in great anxiety, told me that whenever moved or carried about the poor baby began screaming until again replaced in its cradle. On the child being stripped I tound it well nourished and undisturbed by palpation, excepting in one spot a little below the sternum. Here very slight pressure on one particular point induced a fit of screeching which indicated a definite localised trouble. On passing the finger very gently over the tender place I distinctly felt a point which was slightly movable and which was evidently the source of the pain. I at once made a slight incision through the integuments, when to $\mathrm{my}$ surprise a little black point protruded from the wound. This, with a pair of small forceps, I drew out very gently, and to my astonishment I withdrew a small bundle of about 2 inches long, quite black, which $I$ ascertained to be a needle wrapped up in thread. This was at once recognised by the mother as a glover's needle which the child must have swallowed while crawling about the floor, and which had worked its way outwards through the coats of the stomach. The operation over, the child fell fast asleep and recovered in two or three days after parting with this dangerous encumbrance. My wife, who had taken possession of the child during the operation, perfectly remembers this incident which occurred about 50 years ago. Worthing, August 20th, 1911

I am, Sir, yours faithfully,

*** We do not see any reference to the episode in Dr. Ohepmell's interesting letters while he was our valued correspondent in Paris. Dr. Balgarnie writes that the scar at the great curvature of the stomach was situated $1_{\frac{1}{2}}$ in. from the p.ylorus, and not $4 \frac{1}{2}$ in., as printed.-ED. L.

\section{SOME POINTS IN THE TREATMENT OF PULMONARY TUBERCULOSIS.}

\section{To the Editor of THE LANCET.}

SIR,-Whilst enclosing a copy of my annual report, I should like to observe that the perplexities connected with the treatment of pulmonary tuberculosis seem to increase as the years roll on. Personally, I am inclined to think that there are so many differences of opinion amongst authorities because a large number of persons who treat this disease take no precantions to discover whether the disease is active or not. The only method of which I am aware for ascertaining whether the disease is still active or not is to take the rectal temperature before rising in the morning, and if it is not as low as $36.5^{\circ} \mathrm{C}$. $\left(97 \cdot 7^{\circ}\right.$ F.) assume that the morbid processes are still progressing; in arriving at an estimate of the patient's condition very little attention should be given to the patient's remarks about improvement or otherwise, for, as a rule, when the disease is easily curable the subjective symptoms are not marked. From a careful study of the previous histories of these cases I have been forced to the conclusion that chronic fibroid phthisis is the product of exercise taken at a period when the temperature is slightly raised-that is to say, when the products of the tubercle bacillus are of low virulence. If the fever be greater than this, the subjective symptoms will also be considerable, and night sweats will usually be occurring; if exercise be persisted in, a chronic fibroid phthisis will not, as a rule, be produced, but a large amount of caseous material ; these cases may either proceed to a galloping consumption, or the disease may become arrested, leaving the patient in a crippled condition, the amount of crippling being directly proportionate to the antecedent damage. Fibroid destruction of a lung, following upon pleurisy, would seem to be due to an irritant of low virulence acting over a long period. Now if it be granted that all so-called idiopathic pleurisies are tubercular, it is not fair to assume that all cases of plearisy will develop into what is generally understood by the term pulmonary tuberculosis. I suppose a very large number of these cases go on to complete and natural cure. I would suggest, however, in cases of pleurisy of this kind, that the patients be kept in bed until their temperatures reach $36.5^{\circ} \mathrm{C}$ $\left(97 \cdot 7^{\circ} \mathrm{F}\right.$.) before rising in the morning. This method would, I am sure, prevent the development of a large number of serious cases. Of course in the event of such treatment not being successful, recourse might the ${ }_{i}$ be made to tuberculin 